\title{
A Systemic Functional Linguistic Analysis of the Application of Theme and Thematic Progression Patterns in College English Writing Teaching-A Study of Sample Writings of CET-4
}

\author{
Li Yan,"* \\ ${ }^{1}$ Department of College English, Faculty of English, University of Finance and Economics, Inner Mongolia, China \\ *Correspondence: Department of College English, Faculty of English, University of Finance and Economics, Inner \\ Mongolia, China. Tel: 137-047-106-68. E-mail: Julia_317@aliyun.com
}

Received: October 20, 2015 Accepted: December 13, 2015 Online Published: December 17, 2015

doi:10.5430/wjel.v5n4p33

URL: http://dx.doi.org/10.5430/wjel.v5n4p33

\begin{abstract}
Theories of Theme and Thematic Progression are considered important methods which can be widely applied in many aspects of foreign language teaching. Writing teaching is one of the important field in which those theories can be applied. CET-4 is now regarded as a national examination; it has already become the final goal which college non-majors make great efforts to achieve, and also an important method to which teachers can refer in daily writing teaching. Thus the analysis of sample writings of CET-4 will bring lots of benefits not only for passing the exam, but for daily writing teaching. It is found in the study that Themes can yield useful information; successful writings use various Theme types. Besides, thematic choices and TP Patterns help a lot in the realization of cohesion and coherence of discourses.
\end{abstract}

Keywords: Theme; Thematic Progression Patterns; CET-4; Sample writings; Application; Cohesion and coherence

\section{Introduction}

As is known to all, English plays a vital role in lots of aspects in our life. That is why it is called "world language". However, mastering a foreign language like English is still a tough work for a lot of Chinese English learners. Listening, speaking, reading and writing are considered as the four basic skills in learning a language. Among these four skills, writing plays an indispensable role, since writing is a productive process in which it can help learners get to know the correct use of words, phrases and grammar, and help to express their ideas in a clear and systemic way. Greenia (1992: 54) points out that second language writing can facilitate language learning and promote students' thinking ability. Many scholars also argue that written mode is as important as the spoken one in the process of language learning.

Owing to its importance, writing is considered as one of the basic skills that students are supposed to master in the process of their college English learning, it is also included in the college English syllabus. The syllabus made by the Educational Commission of China requires that college non-English majors should produce writings which are complete in content, appropriate in diction and coherent in discourse after two-year learning. Writing also plays an essential part in many standardized English tests, such as College English Test (CET), Test for English Majors (TEM). Hence, how to write well is always the focus in the field of English learning and teaching.

\section{Data and Methodology}

\subsection{Data}

A total number of 22 published sample writings of CET-4 were selected and analyzed for the present study. Those samples were published from June 2001 to September 2011 by Beijing Qunyan Press. Comparing with the samples from different published sources, which serve for the same topic, i.e. for the title Nothing succeeds without a strong will (2011.12), tens of different versions of sample writings can be found, the study holds that in daily writing teaching, teachers and students will meet different genres with different requirements. Choosing samples with 
various genres will better serve the purpose of this study.

Typical CET-4 writings mainly include argumentations, expositions and letters. In the collection of sample writings, announcements also appeared, but they will not be included in the research because they constitute a very small proportion.

After classifying the samples according to the genre type, the thematic choices will be compared and analyzed based on different classification of Themes. Besides, thematic Progression Patterns of different type of writings will then be put into detailed analysis.

\subsection{Methodology}

First, all the collected samples are classified into different genre types: argumentation, exposition and letter.

Second, all the Themes of main clauses appearing in the sample writings are counted, and then classified based on different Theme types, i.e., marked Theme, unmarked Theme, simple Theme, multiple Theme,etc,. What proportion different Theme types constitute will also be analyzed.

Third, TP Patterns of the samples would be analyzed and compared to see whether certain pattern would be prominent in certain kind of writing. Therefore, some features might be found in such type of writing.

Here are some important detailed principles on which the study and analysis reported in the following part are based:

I Only themes of main clauses are considered. Halliday (1985: 62) asserts that "the main contribution comes from the thematic structure of independent clauses". Besides, space for this paper is limited, so it seems sensible to concentrate on those Themes generally agreed to be signifcant for text organization and genre awareness.

II. Only declarative, imperative and interrogative main clauses are analysed, since they constitute the major parts in the sample writings.

III. While there is general agreement in the paticular tradition of thematic analysis that

the Theme of a clause is at the beginning of the clause, practice varies widely over how much of a clause to count as the beginning. This theis is bold enough to err the side of generosity and includes in the Theme everything that anyone working in the Hallidayan tradition has ever advocated including. This means that the paper has treated as Theme everything precedes the main clause, this too has been included. ( see Ravelli, 1996).

\subsection{Objective and Research Questions}

\subsubsection{Objective}

The eventual aim of the paper is to find out the feasibility of application of Theme and TP Patterns in college English writing teaching. In the process of analyzing the application of Theme and TP Patterns, different objectives might be fulfilled through the study of CET-4 sample writings :

I. discover the features that successful writing own.

II. make the findings of the research available in a form which will enable Chinese college English teachers to assess and guide the process of their students towards likely success in the writing.

\subsubsection{Research Questions}

This paper combines qualitative and quantitative studies on the application of Theme and TP Patterns. Despite the possible limitations and inadequacy of the study, it is still hoped that answers might be found for the following questions:

I. Is Theme an apect of language which can yield useful information.

II. Should successful writings have various theme types?

III. Does TP correlate with genre type?

IV. In what aspect and how can TP improve English writing of college English?

V. With the help of different types of TP Patterns, could writings become more logical and coherent?

\section{Studies on Theme and Thematic Progression}

\subsection{Identification of Theme and Rheme}

Halliday defines Theme in the following way: "The Theme is the element which serves as the point of departure of 
the message; it is that with which the clause is concerned". It is clear that the notions such as "starting point" or "point of departure" are metaphorical and difficult to interpret. Indeed, many discussions of Theme simply ignore or dismiss these wordings. Huddleston, for example, dismisses this part of Halliday's description with the sentence: It is not clear that "point of departure" or "starting point" can sustain an interpretation that is indepentent of syntactic sequence, that the Theme is the point of departure for the message in a more significant sense than that of being the first element.

Halliday describes the Theme-Rheme dichotomy. First, the Theme is marked in intonation as a separate tone unit, frequently followed by a brief pause. Second, only the basic elements of the kernel structure can become topic Themes: the process (main verb), the participants (subject and object) and the circumstantial factors (adverbials).

To make it simple, Theme is the first constituent of the clause, all the rest of the clause is simply called the Rheme; see table 3.1

Table 3.1 Theme and Rheme

\begin{tabular}{ll}
\hline You & probably haven't heard of the SOU before. \\
Yellow canaries & have been used to 'test' the air in the mining for centuries. \\
\hline Theme & Rheme \\
\hline
\end{tabular}

\subsection{Classification of Theme}

Theme can be classified according to their metafunctional type, under this parameter, Theme is annotated as textual, interpersonal and ideational. According to Halliday (1967: 234), textual Theme is any combination of continuative, structural and conjunctive elements. Interpersonal Theme is any combination of vocative modal and mood marking. Ideational theme is the beginning of the clause up to and includes the first element that has a function in transitivity.

Theme can also be classified according to their semantic type. Which means that Themes can represent Circumstances, Participants or Processes in the ideational structure of the clause as Halliday has mentioned in his work. Finally, the degree of

markedness within the structure of the clause is another parameter to classify

Themes. The following classifications are based on the three parameters, but also combine other ways from Thompson (2004: 144-160) which are considered helpful in fulfilling the paper.

\subsubsection{Textual, Interpersonal and Ideational Elements in Theme}

"The textual and interpersonal elements signal how the fitting-in is going to work; they don't signal what is going to be fitted-in" (Thompson 2004: 159). The most frequent textual Themes are continuative elements such as yes, no, well, oh, now, coordinators such as and, or, but or subordinators such as when, after, if; structural elements such as yet, so, even if, conjunctive adjuncts like however, moreover, also, therefore, in other words, as far as and next are also used. Interpersonal element incorporates modal element such as certainly, broadly speaking, finite element in interrogative sentence and vocative elements such as John, Mrs. Jone, ladies and gentlemen. Besides, interpersonal Theme represents the writer's evaluation of the preposition that is being made. Ideational element refers to topical element which is the last constituent in multiple thematic structure, which also means that Theme must always include a constituent that plays a role in transitivity: a participant, process or circumstance. See the following table:

Table 3.2 Multiple Themes

\begin{tabular}{llll}
\hline Well, & certainly, & sanity & Is a precarious state. \\
& My God, Harriet & we & 've been dealt a bad hand! \\
But & surely & the course & doesn't start till next week. \\
And, & oddly, & he & was right. \\
textual & interpersonal & ideational & \\
\cline { 1 - 2 } Theme & & & Rheme
\end{tabular}

As is indicated in the above table, there is an order for multiple Theme, i.e. textual ${ }^{\wedge}$ interpersonal ${ }^{\wedge}$ ideational $^{\wedge}{ }^{\wedge}$ means followed by). We can have combinations such as textual ${ }^{\wedge}$ ideational, interpersonal ${ }^{\wedge}$ ideational, or the ideational on its own. We must have an ideational Theme in every case. The other elements are optional. 


\subsubsection{Circumstances, Participants or Processes Elements as Theme}

Themes can be annotated according to their semantic function within the transitivity structure of the clause. Thus, Themes could represent Circumstances, Participants or Processes in the ideational structure of the clause as Halliday has mentioned in his work. See table 3.3, 3.4, 3.5:

Table 3.3 Circumstance as Theme

\begin{tabular}{ll}
\hline What days & are you free? \\
\hline Theme & Rheme \\
\hline
\end{tabular}

Table 3.4 Participant as Theme

\begin{tabular}{ll}
\hline I & will visit the muesum \\
\hline Theme & Rheme \\
\hline
\end{tabular}

Table 3.5 Process as Theme

\begin{tabular}{ll}
\hline Gonna find & who ever schedules, me or that, and shoot them. \\
\hline Theme & Rheme \\
\hline
\end{tabular}

\subsubsection{Marked and Unmarked Theme}

There are different types of Themes. It frequently happens that the Theme in a clause coincides with the subject as table 2.4 shows (they are said to be "conflated"). Subject is the "normal" Theme choice: it is the constituent that is chosen as Theme unless there are good reasons for choosing something else. If this happens, we have an "unmarked" Theme. But it is also possible to have another constituent placed intially in a clause. If this is the case, we have a "marked" Theme as the examples in table 3.6 show, because they are unusual enough to draw attention to themselves, and because they only occur when contextual reasons overrule the unmarked choice of Subject as Theme.

Table 3.6 Marked Theme

\begin{tabular}{ll}
\hline All the rest & we'll do for you \\
What I saw inside & I don't want to describe \\
\hline Marked Theme & Rheme \\
\hline
\end{tabular}

\subsubsection{Theme in Declarative and Non-Declarative Clauses}

As it is known to all, the Subject in a clause may be fairly extensive, for example, the nominal group acting as Subject includes a long Post-modifier. In the case, it is the whole nominal group that is Theme. The subject may also be a nominal group complex, where, for example, two co-ordinated nominal groups function together as Subject: again, the whole group complex in a single clause constituent and thus functions as Theme (see the first example in table 3.7). In some cases, the Subject may be an embedded clause, as in the second example below.

Table 3.7 Theme in Declarative Clause

\begin{tabular}{|c|c|}
\hline $\begin{array}{l}\text { The interest in the book, familiarity with the working of the } \\
\text { organization }\end{array}$ & would be a strong advantage \\
\hline $\begin{array}{l}\text { Sending the final result through to Faculty before all the } \\
\text { documents have arrived }\end{array}$ & will $\mathrm{p}$ \\
\hline Theme & Rheme \\
\hline
\end{tabular}

The other kind of constituent that is relatively often chosen as Theme in declarative clauses is an Adjunct. Unlike Subject and Complement, which often occur in a relatively fixed order in relation to the Predicator ("Subject-Verb-Object" in traditional terms), the position of Adjunct is fairly flexible, and they can be placed in Theme without this seeming particularly unusual or marked compared with the choice of Subject as Theme. 
Sometimes, Adjuncts could usually not move so easily into the Subject role. Because of the flexibility of their position, when an Adjunct is used as a Theme, as table 3.8 shows, it is somewhere in the middle to the scale of "markedness". However, for simplicity Adjuncts are labelled as marked Theme (see Halliday \& Matthiessen 2004: $73)$.

Table 3.8 Adjunct as Theme

\begin{tabular}{ll}
\hline Last week & we went to visit my grandfather. \\
As a teacher & I hope to get improved in my proffesional work. \\
\hline Theme & Rheme \\
\hline
\end{tabular}

The other main type of clause is interrogative. With WH-interrogatives, the WH-word or group itself represents the missing information that the other person is being asked to provide. In questions the natural starting point is the thing that the questioner wants to know about, and therefore it is the WH-word or group that almost invariably appears in Theme- position.

Unlike Theme in declarative clauses, the type of clause constituent does not affect markedness. A marked Theme choice in a WH-question occurs when the WH-word or group does not come in first position. However, since the structure of interrogative clauses is specifically designed to bring the WH-element to first position, marked Theme choices are relatively rare with questions; see table 3.9.

Table 3.9 Theme and Marked Theme in WH-questions

\begin{tabular}{ll}
\hline What & happened to her? \\
After the party & Where did you go? \\
\hline Theme & Rheme \\
\hline
\end{tabular}

There are some further types of non-declarative clauses like imperative. Marked Theme is rather more common with imperative clauses than with other non- declarative types, see the first two examples in table 3.10. Normally, the addressee of an imperative clause is the understood doer of the action. Besides, an imperative clause may start from an Adjunct, which is supposed to give an explanation of why the command should be carried out. Table 3.10 gives examples of some possibilities.

Table 3.10 Theme in Imperative Clauses

\begin{tabular}{ll}
\hline You & just shup up, will you? \\
On arrival in Beijing & take a taxi to the bird nest. \\
Leave & the table there. \\
Don't & cry about it \\
Let's & do it together, shall we? \\
\hline Theme & Rheme \\
\hline
\end{tabular}

\subsubsection{Special Thematic Structure}

So far, all the Themes that we have examined have consisted of a single clause constituent. However, there is a textual resource in English by which means the speaker can group together more than one element of the message as a single constituent, and then use that "multi-element constituent" as Theme. Halliday and Matthiessen (2004: 69) prefer to call this structure a "thematic equative", because the Theme-Rheme structure here is expressed in the form "Theme=Rheme", with "=" expressed by the Predicator "be".

Table 3.11 Thematic Equative

\begin{tabular}{ll}
\hline What I'm going to do now & $\begin{array}{l}\text { is to go to the library } \\
\text { is anything about the Enlightenment }\end{array}$ \\
\hline What one will not learn here & Rheme \\
\hline Theme
\end{tabular}


One key feature of thematic equative is that they group more than one element of the message into a single clause constituent that can then function as Theme. There is another thematizing structure that allows the speaker to pick out a single element and give it emphatic thematic status. This is the structure exemplified in table 3.12 , which is preferred by Halliday and Matthiessen (2004:95) as 'predicated Theme'.

Table 3.12 Predicated Theme

\begin{tabular}{ll}
\hline It is I & $\begin{array}{l}\text { who have helped the boy. } \\
\text { th was not untill } 1980\end{array}$ \\
\hline Theme & Rheme \\
\hline
\end{tabular}

Another special thematic structure, which in some ways resembles predicated Theme, allow speakers to start their message with their own comment on the value or vadality of what they are about to say. It is called "thematized comment". Here are typical examples:

Table 3.13 Thematized Comment

\begin{tabular}{ll}
\hline It is difficult & $\begin{array}{l}\text { to believe such kind of thing. } \\
\text { that they took six years to do so. } \\
\text { that he can not come for today's party }\end{array}$ \\
\hline Theme & Rheme \\
\hline
\end{tabular}

\subsubsection{Simple and Multiple Theme}

Theme can also be classified according to their internal structure. In the first and second examples of the following table, we have two "simple" Themes, but we can also have "multiple" Theme structures. A simple Theme always has an ideational element in it. A multiple Theme has more than one element as in the third and fourth examples in table 3.14. In 2.3.2.1, we have mentioned multiple Themes. There might be the situations that a multiple Theme goes beyond the classification of textual, interpersonal and ideational elements. That is why simple and multiple Themes are mentioned here separately.

Table 3.14 Simple and Multiple Theme

\begin{tabular}{ll}
\hline They & will never give up until they succeed. \\
We & can name a lot of famous singers. \\
But all rooms & look out onto the garden. \\
After five minutes & he came out of the door \\
\hline Theme & Rheme \\
\hline
\end{tabular}

\section{Studies on Thematic Progression}

The first researcher who studied the TP was Denmark linguist F. Danes. He argued that "the organization of information in texts is determined by the progression in the ordering of utterance Themes and their Rhemes." (Danes, 1974). The connection and change between successive Themes and Rhemes is called "Thematic Progression".

In 1976, with the publication of Cohesion in English by Halliday and Hasan, people with an ever-increasing number realized that a coherent text was not an accumulation of a series of grammatically correct sentences, it is a combination of interrelated sentences and each sentence is build on the preceding ones. In this way the discourse advanced.

\subsection{The Application of TP Patterns}

Some other linguists also got involved in the research of TP. Van Dijk (1981:231) focused his attention on TP and text organization of news report. Martin (1985: 97) studied the relationship between text organization patterns and register from the point view of TP. Nwogu (1991) investigated the TP patterns in medical text. McCarthy (1991:287) showed how an advertisement for time-share holidays utilized contrastive thematic structure within the same text. TP had been employed in the analysis of different text types. Fries and Peter (1995: 317) argued that TP correlated with 
the structure and the method of development of a text. In 1992, they stated that different types of TP correlated with genres. Francis'(1989:211) studies were also related to the correlation between thematic content and genres.

TP Patterns have been employed in the analysis of different text types. Hatim (2001: 13) published the book Communication across cultures: translation theory and contrastive. In this book, he pointed out that TP theory is a useful tool to understand and analyze the organization of a text.

In china, a lot of attention of many domestic scholars and teachers had been put on the TP Patterns and application of it in foreign language teaching and learning, such as Hu Zhuanglin, Huang Guowen, Zhu Yongsheng, Liu chendan, Zhang Delu, ,etc,. They all contributed a lot to the study of TP patterns and application to various studies.

$\mathrm{Xu}$ (1982) first discussed the relationship between Theme-Rheme and translation. In his opinion, Theme and Rheme helped to understand the original text and contributed to translation practice. Li (2002) studied the relationship between cohesion devices and reading comprehension and how to help students improve their reading ability by the way of analyzing cohesion devices in test. Wu (2000) explored the application of thematic theory in reading and writing, especially the relationship between cohesion, coherence, and control in English reading and writing. Liu (1999) and Zhu (1995) further studied the English foreign language reading and Theme-Rheme theory. These investigations in TP and its application give us a new insight into the learning and teaching of English reading, writing, translation and genre analysis.

\subsection{Types of TP Patterns}

Based on his notion mentioned above, Danes then proposed four major TP Patterns: simple linear pattern, TP with a constant theme, TP with derived themes, the split rheme pattern. Danes' TP theory was introduced to China in 1980s, which aroused great interests of Chinese scholars. Following Danes' research, Chinese researchers developed the TP patterns into various models from different perspectives.

$\mathrm{Hu}$ (1994: 117) stated his three models of TP briefly: (1) repeated Theme pattern, (2) repeated Rheme pattern and (3) repeated Theme and Rheme as successive cohesive devices; Zhu (1995) suggested four basic types of TP: (1) parallel pattern (the constant Theme pattern) (2) concentrated pattern (the same Rheme pattern) (3) continuous pattern (the simple linear pattern) (4) alternative pattern (the intersection pattern). In this paper, Danes', Huang's and Zhu's models are put together so as to demonstrate a more comprehensive analysis.

(1) Parallel Progression

In this model, the Theme of the first clause is the Theme of the following clauses.

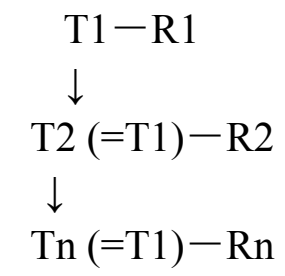

e.g My English teacher is from Shanghai. She graduated from Fudan University in 2005. She works as an English teacher....

(2) Continuous Progression/ simple linear pattern

In this model, the Rheme of the previous clause becomes the Theme of the following sentence.

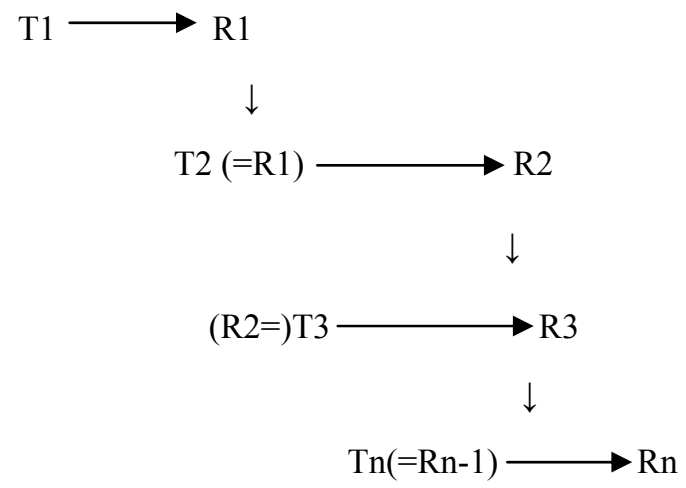


e.g My friend bought me a gift. It is a beautiful bag of Gucci. Gucci is a famous bag maker.

(3) Intersectional Progression

In this model, the Theme of the previous clause is the Rheme of the following clause.

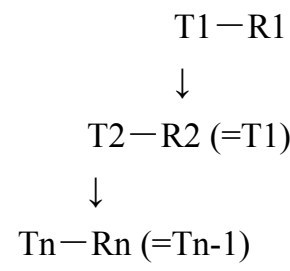

e.g. The new house is luxurious, but $\underline{I}$ don't like it. The noisy surroundings annoy $\underline{\text { me. }}$.

(4) Coordinate Progression

In this model, the Themes of the clauses in odd number are the same, while those in even number are the same.

$$
\begin{aligned}
& \mathrm{T} 1-\mathrm{R} 1 \\
& \mathrm{~T} 2-\mathrm{R} 2 \\
& \mathrm{~T} 3(=\mathrm{T} 1)-\mathrm{R} 3 \\
& \mathrm{~T} 4(=\mathrm{T} 2)-\mathrm{R} 4
\end{aligned}
$$

e.g. Americans eat with knives and forks; Japanese eat with chopsticks. Americans say"Hi,"when they meet; Japanese bow. Many American men open door for women; Japanese men do not.

(5) Derived Theme

In this model, the Themes of the following sentences are parts of the first Theme, i.e., synonyms, antonyms, hyponyms

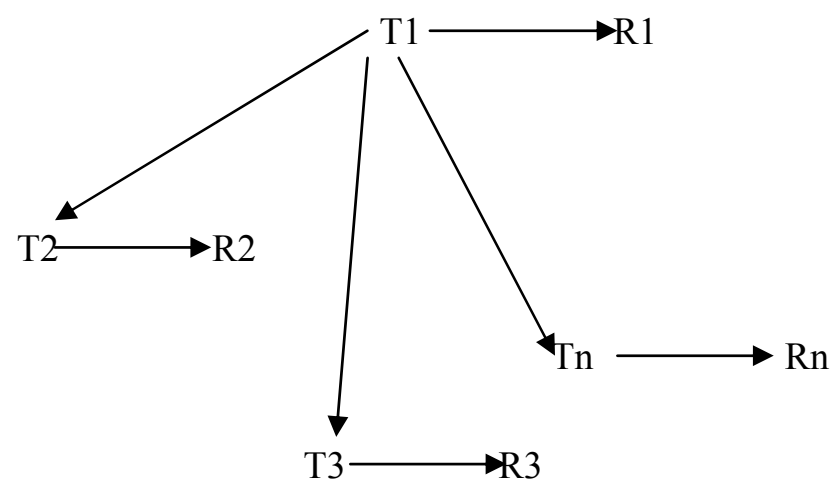

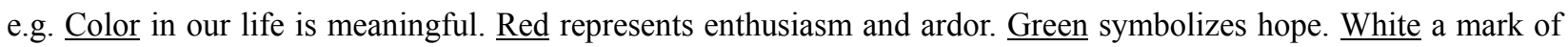
chasteness.

(6) Concentrated Progression

In this model, the Rhemes of all clauses are the same.

$$
\begin{array}{r}
\mathrm{T} 1-\mathrm{R} 1 \\
\downarrow \\
\mathrm{T} 2-\mathrm{R} 2(=\mathrm{R} 1) \\
\downarrow \\
\mathrm{Tn}-\mathrm{Rn}(=\mathrm{R} 1)
\end{array}
$$


e.g England is a country; France is a country; Norway is another country; Turkey is another country; Egypt, Italy, Poland are other countries.

(7) TP with a constant Theme

In this model, the Rheme of the first clause is the Theme of the following sentences.

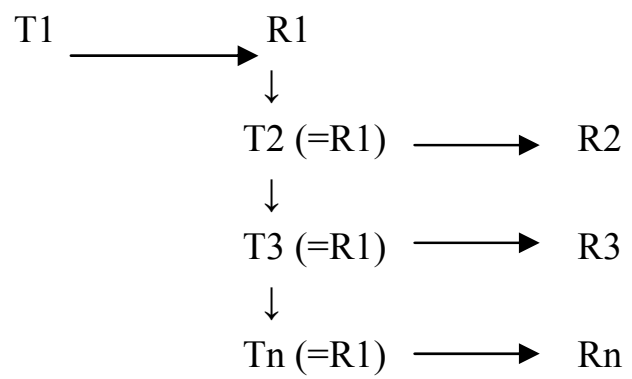

e.g. My mother and I prefer to live in the suburb than the downtown for a number of reasons. The first reason is that.... The second reason is that .... The third reason ....

(8) The split rheme pattern.

In this model, some Themes of following sentences are parts of the Rheme of the first sentence, i.e., synonyms, antonyms, hyponyms.

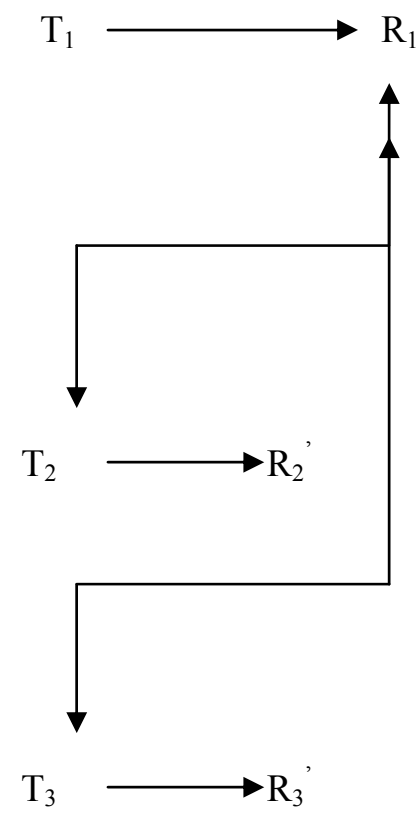

e.g. Mary likes reading books. Novels are her favorite ones to read. Magazines are the ones for collecting beautiful pictures.

\section{Studies on Writing TeachingAapproaches at Home and Abroad}

\subsection{Approaches in and out of China}

Writing is a productive skill, which often seems to be the hardest skill even for native speakers of a language. It is such a complicated technique, perception and social process that formalist is not helpful enough. Anyhow, a good form is far from perfect for a piece of good writing.

In the early time of 1900s, "Current- traditional" approach, which was also known as product-oriented writing, was put forward by Daniel Fogarty and James Berlin, etc,. As its name has implied, this approach puts much more concern on the product of the writing rather than process. The goal of this approach is to teach students to produce the written texts which they will frequently encounter in their daily life. Students are supposed to imitate the 
rhetorical patterns and grammatical rules presented in the model writings. Table 5.1 shows the detail.

Table 5.1 Product-oriented Writing Approach

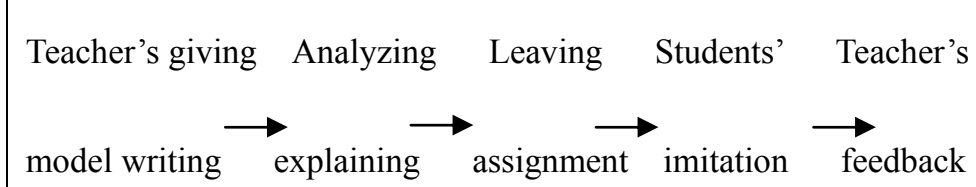

In 1970s, another approach, "process" approach came into being. In which students and students' need are taken as the point of departure. Brainstorming, planning, drafting, peer-conferencing and peer-editing are included in the writing process. Teachers are supposed to hold that writing is learnt but not taught, and the teacher's role is to be non-directive and facilitating, providing writers with the space to make their own meanings through an encouraging, positive and cooperative environment with minimal interference.

Table 5.2 Process-oriented Writing Approach

Pre-writing $\longrightarrow_{\text {Drafting }} \longrightarrow_{\text {Revising }} \longrightarrow_{\text {final drafting }} \rightarrow_{\text {Teacher's feedback }}$

Unfortunately, as North (1987: 85) points out, this approach offers no clear theoretical principles from which to evaluate "good writing", nor furnishes advice that can help accomplish it.

Chinese scholars Hu (1994: 125), Cheng (1994: 66), etc., make a contrast study between "product" approach and "process" approach, arguing that to a certain extent, both the approaches could improve the students' composing ability. Therefore, they make a suggestion to combine the two approaches together and use them in English writing teaching.

Wu (2000) and Wang (2002) after considering the practical condition of domestic writing teaching, research the feasibility of three new teaching methods, namely process approach, genre approach and process-genre approach. They believe that, through these steps, students can separately or simultaneously get necessary writing knowledge and input of skills from model articles. The teaching process can not only develop the guiding function of the teachers and model articles, but also stimulate students' initiative.

However, there are still no obvious improvements appearing among Chinese students'English writing despite the fact that there have been great development of English writing researches in China. This situation can be proved by the relatively low marks of English writing in CET-4 and CET-6. The two examinations are held twice a year among non-English majors. For nearly ten years in the past the average mark of English writing in many important and influential universities bounced between 5 and 7, while the total mark is 15. Although there are improvements in recent years, the writing score has not reached 9, the passing line (Ren, 2005).

\subsection{Systemic Functional Approach}

Discourse refers to the purposes and functions linguistic forms serve in texts. A variety of approaches have considered texts as discourse, but all have sought to discover how writers use patterns of language options to accomplish coherent and purposeful writing. An important early contribution is the work by the Prague School into ways in which clauses are structured to present the writer's assumptions about what is known (given) or new to the reader (see Firbas 1986). This "functional sentence perspective" is taken up and elaborated in the work of Halliday (1994: 78) and other SFL in the concept of Theme-Rheme structure.

Roughly, Theme is what the writer is talking about and Rheme what he or she saying about: the element of the message that the writer considers important. An analysis of these shows how writers organize clauses into information units that push the communication forward through a text. Ideas are made easier for readers to follow, in some genres at least, when thematic choices are not unexpected but are related to ideas they have met in the Theme or Rheme of an earlier clause. In other words, we generally expect writers to present old information first as a context for new, so in (1), for instance, the thematic information of the second sentence (a) is also the Theme of the previous sentence, while in (2) the Theme of the second sentence (b) occurs as the previous Rheme. 
(1) Limiting their usage is of great importance. It helps protect the living

(a)

surroundings. (b) (c)

\section{(2) $\underline{\text { A week ago I saw a traffic accident. It was about 9:00 on Saturday }}$}

(a)

morning. (b) (b)

(c)

In (3), the topic of the writing is introduced in the Theme of the first sentence. It then appears as part of the Rheme in the second sentence. The Themes of the final sentence, however, breaks the sequence by placing "they" as Theme, clearly signposting the progression.

(3) Disposable plastic bags were once widely used everywhere. When people went shopping, the stores, supermarkets and even some vendors offered bags to them to carry the goods. In addition, they had always been utilized as a temporary package for daily stuff, and they were considered to be an indispensable tool of life and work. (From the sample writing of December. 2008)

\section{Analysis on Sample Writings of CET-4}

According to Halliday (1985: 154), the choice of clause Theme plays a fundamental part in the way discourse is organized. In the following part, what type of Themes is chosen, what kind of TP Pattern is applied in different genre types will be analyzed, aiming to see how the fluency, cohesion and coherence of the text will be affected by different thematic choices and TP Patterns.

\subsection{An Analysis on Thematic Choices}

An example of sample writing from october 2011 is given first about the thematic choices.

Direction: For this part, you are allowed 30 minutes to write a short essay entittled Nothing Succeeds Without a Strong Will by commenting on the humorous saying, "Quitting smoking is the easiest thing in the world. I've done it hundreds of times." You should write at least 120 words about no more than 180 words.

\section{Nothing Succeeds Without a Strong Will}

It is known to us all that where there is a will, there is a way. A person can probably accomplish nothing without a strong will. We can't deny that sometimes people can reach a goal by playing tricks; however, that definitely won't last long.

People with strong wills cannot be defeated by difficulties easily and they will never give up untill they succeed. Take Nobel, the inventor of explosive, as an example, before inventing explosive he took thousands of explosion experiments. We can name quite a lot of famous people like Nobel, but we can also list some people like the "smoking quitters". To them, making a plan is so easy as they don't have to keep it. Therefore, they will never realize it.

To sum up, a strong will is an important character people should cultivate since it plays a key role in people's success. The resolute make resolutions once and for all; the irresolute keep making resolutions all for once. To be the winner, try to be the resolute.

The following table shows clearly different Theme types of the above samples: 
Table 6.1 Thematic Choices of the Sample Writing

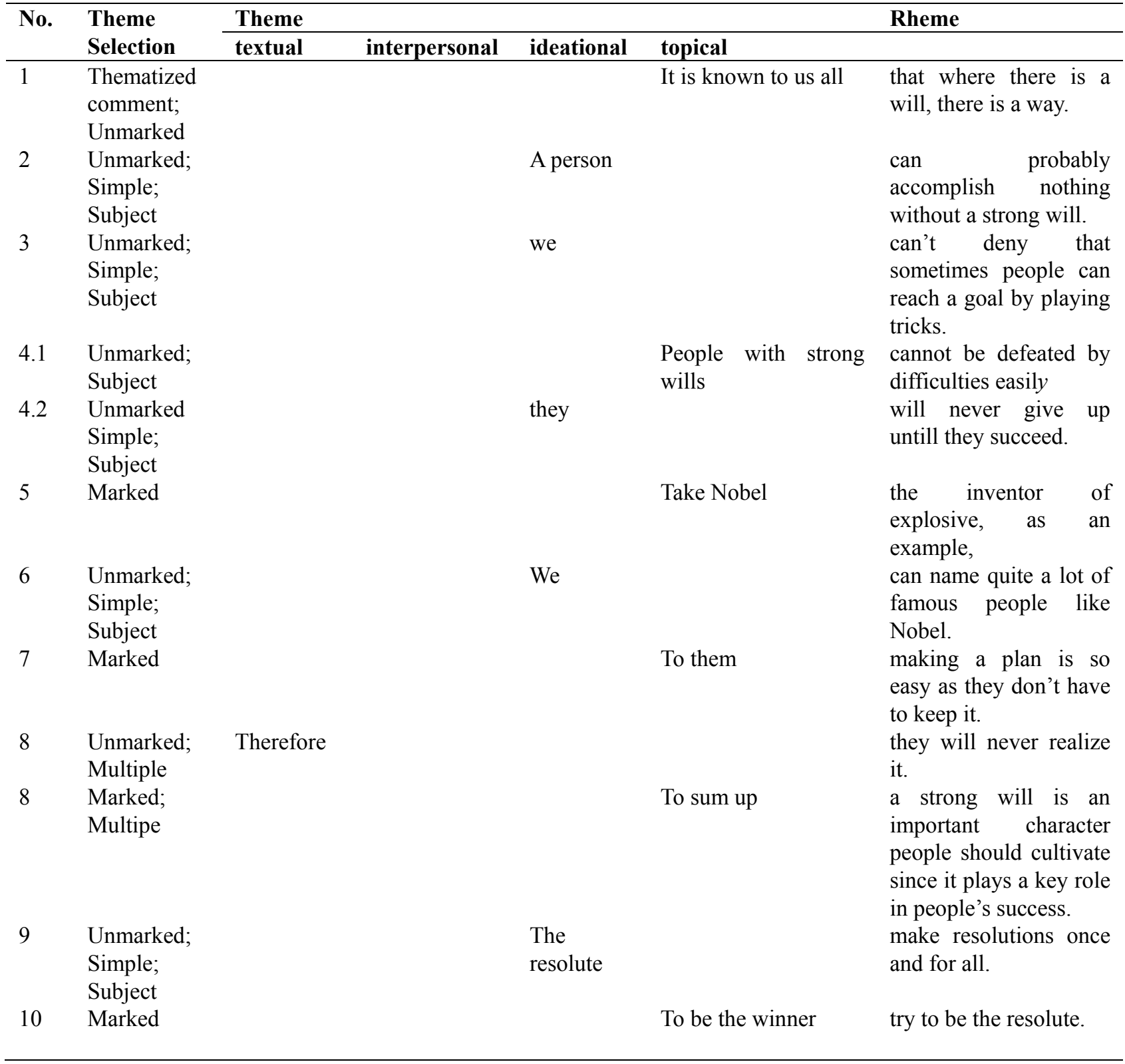

As is mentioned above, argumentations, expositions and letters are included in this research, the following analysis will be divided according to different genre types of the writing samples. The following tables summarize the findings of all the 22 sample writings . The results will then be analyzed and compared.

Table 6.2 Textual, Interpersonal and Ideational Element as Theme

\begin{tabular}{lllllll}
\hline \multirow{2}{*}{ Theme } & \multicolumn{2}{l}{ Argumentation } & Exposition & Letters & \\
\cline { 2 - 7 } & No & $\mathbf{\%}$ & No & $\mathbf{\%}$ & No & $\mathbf{\%}$ \\
\hline Total & $\mathbf{7 0}$ & & $\mathbf{9 9}$ & & $\mathbf{3 6}$ & \\
Textual & 7 & 10.0 & 15 & 15.2 & 1 & 2.8 \\
Interpersonal & 3 & 4.3 & 2 & 2.0 & 0 & 0 \\
Ideational & 10 & 14.3 & 17 & 17.2 & 2 & 2.8 \\
\hline
\end{tabular}

According to Halliday (1994: 36), textual element is used to create relevance to context, ideational element is to construe a model of experience, interpersonal element is to enact social relationships. As can be seen from the above 
table that the three elements constitute larger part in argumentation and exposition. Argumentation is used to convince the reader of a writer's argument(s) relating to a debatable issue. Argumentative writing involves convincing the reader to perform an action, or it may simply consist of an argument(s) convincing the reader of the writer's point of view. In other words, the readers need to be convinced by the arguments, by what has been shown in the context; exposition mainly focuses on introducing truthfully objective things, explaing briefly, striving to make things known to readers. That explains why there are more textual elements in these two types of writing, readers need to know what it is in the text, it is the task of textual element to produce related information and to organize the presentation of their message about the context.

In SFL, interpersonal Themes are described as clause initial items used by writers to exchange roles in rhetorical interactions with their addressee(s), and to express their own angle on the matter, that is, accompanying degrees of modalisation (i.e. probability) or modulation (i.e. inclination and obligation). Argumentation and exposition are such kind of writings which certainly show writers' ideas and opinions with more of less modalisation and modulation.

As for ideational element, it construes quanta of change within the flow of events. (cf. Halliday \& Matthiessen 2004: 257). In order to show clearly the arguments, express clearly the ideas, both argumentative and expositive writings will change their subjects when it is necessary. All these can be examplified by the following examples:

(1) Generally speaking, every employer wants his employees to be honest. (2003.1) interpersonal ideational

(2) However, the downsides should not be ignored.

textual ideational

Table 6.3 Circumstance, Participant, Process Element as Theme

\begin{tabular}{lllllll}
\hline \multirow{2}{*}{ Theme } & \multicolumn{2}{l}{ Argumentation } & Exposition & \multicolumn{2}{l}{ Letters } \\
\cline { 2 - 7 } & No & $\mathbf{\%}$ & No & \% & No & \% \\
\hline Total & $\mathbf{7 0}$ & & $\mathbf{9 9}$ & & $\mathbf{3 6}$ & \\
Circumstance & 16 & 22.9 & 28 & 28.3 & 9 & 25.0 \\
Participant & 20 & 28.6 & 32 & 32.3 & 15 & 41.7 \\
Process & 1 & 1.4 & 5 & 5.1 & 1 & 2.8 \\
\hline
\end{tabular}

Circumstances contribute additional, and frequently optional information regarding who, when, where, how, for how long, and so on, of the process. They are typically realized by adverbial and prepositional phrases (e.g. last Saturday, very quickly, on my pillow, before the meeting).

Participants are those elements which denote who or what is directly involved in the process. They are typically realized by noun phrases (e.g. the man, Margaret, my left foot, an interesting book).

Processes are the happenings or states of affairs represented in a clause. They are realized by verb phrases (e.g. went, started crying, will be singing, drank).

According to the above table, argumentation, exposition and letter use large percentage circumstance elements as Theme. This is determined by the nature of these writings. Argumentation and exposition tend to use more adverbial phrases and prepositional phrases to make the writing more readable and convincing. Letters surely need more information about who is doing what, how things are going, etc,. Participant elements must appear in all the three kinds of writings since there will be no articles in which there are no any participants like who and what.

Expositions have more process elements, which is partly due to the fact that expositive writings need more explanations about events, processes to express what the writer want to say, while the other two types do not. For example:

(3) To begin with, English is the most popular language in the world.

(2004.6)

circumstance

(4) Some individuals deem that it should be canceled or replaced by other programs participant (2006.12)

(5) Get dressed properly and neatly. (2001.1) process

(6) Reading this chart, we can find that the average number of hours student spends 
process

on the computer per week has increased sharply.

(2002.6)

Table 6.4 Marked and Unmarked Themes

\begin{tabular}{lllllll}
\hline \multirow{2}{*}{ Theme } & \multicolumn{2}{l}{ Argumentation } & Exposition & \multicolumn{2}{l}{ Letters } \\
\cline { 2 - 7 } & No & $\mathbf{\%}$ & No & \% & No & \% \\
\hline Total & $\mathbf{7 0}$ & & $\mathbf{9 9}$ & & $\mathbf{3 6}$ & \\
marked & 9 & 12.9 & 17 & 17.2 & 9 & 25.0 \\
unmarked & 19 & 27.1 & 37 & 37.4 & 26 & 72.2 \\
\hline
\end{tabular}

Table 6.5 Adjunct, Subject, Complement as Theme

\begin{tabular}{lllllll}
\hline \multirow{2}{*}{ Theme } & \multicolumn{2}{l}{ Argumentation } & Exposition & Letters \\
\cline { 2 - 7 } & No & $\mathbf{\%}$ & No & $\mathbf{\%}$ & No & $\mathbf{\%}$ \\
\hline Total & $\mathbf{7 0}$ & & $\mathbf{9 9}$ & & $\mathbf{3 6}$ & \\
Adjunct & 2 & 2.8 & 16 & 16.2 & 7 & 19.4 \\
Subject & 21 & 30 & 39 & 39.4 & 28 & 77.8 \\
Complement & 0 & 0 & 0 & 0 & 0 & 0 \\
\hline
\end{tabular}

There are ralatively more marked Themes in exposition and letters than in argumentation. Letters have the largest percentage of unmarked Theme, exposition ranks the second, and argumentation the third.

In Thompson's (2004:164) classification, three syntactic structures, namely, Dependent Clause as Theme, Adjunct as Theme, and Complement as Theme, belong to marked Themes. Except Complement as Theme, the other two structures are traditionally categorized as adverbials. It is generally considered that adverbials are morphologically and syntactically the most diverse grammatical structures in English (see Celce-Murcia, M. \& Larsen-Freeman, D, 1999); thus, it is likely that the placement of adverbials, either before or after the main clauses, is decided by discourse function rather than by random arrangement. In other words, unmarked Themes appear at the beginning of a clause most naturally and commonly, why marked themes are chosen in discourse? According to Kopple (1991: 256), writers occasionally select marked Themes for two reasons. One reason is to place information from earlier parts of the text at the beginning of a clause, and the information is recoverable (that is, given information). By doing so, writers are able to express new information at the end of a clause and the new information in turn can be expanded upon in subsequent sentences. That is why in exposition and letters, there are more marked Themes. Both of them want to use words that clearly show what they are talking about rather than blatantly telling the reader what is being discussed. The other reason is "to call attention to bits of information or to invest them with a highly charged quality" (Kopple 1991: 321). In some other investigations, discourse factors have been found to affect the positions of adverbial clauses: foreground/background information structure, the scope of dependence of subordinate adverbial clauses, topic continuity of neighboring clauses, and time sequence of described events. Although Kopple (ibid) focuses on the syntactic structures of complement and adjunct whereas others put more emphasis on that of adverbial clause, concerning the occurrence of marked themes, they share something in common in that Kopple's first reason is broad enough to cover the other scope of dependence and topic continuity. Here are the examples of marked Theme:

(7) With the development of technology, online shopping becomes a fashionable trend in our life. (2011.6)

(8) Nowadays, there are barious courses that students could freely choose in colleges and universities. (2007.12)

(9) Undoutedly, there are a lot of dilicious dishes, but all the year round, they are the same. (2002.1)

As the above examples show, most marked Themes are arranged in the initial position of sentences so that personal stories or events can be narrated in order of time. Comparaing with marked Theme, all the three kinds of writing have many more unmarked Theme. Letters have the largest number of unmarked Theme, which is three times of the marked ones, the other two have about two times of the marked Theme. It shows that unmarked Themes are more common in various writings, but marked Themes are absolutely needed to make the writings more diverse and readable. 
Table 6.6 Special Thematic Structures

\begin{tabular}{lllllll}
\hline Theme & \multicolumn{2}{l}{ Argumentation } & Exposition & \multicolumn{3}{c}{ Letters } \\
\cline { 2 - 7 } & No & $\mathbf{\%}$ & No & $\mathbf{\%}$ & No & \% \\
\hline Total & $\mathbf{7 0}$ & & $\mathbf{9 9}$ & & $\mathbf{3 6}$ & \\
Thematic equative & 0 & 0 & 0 & 0 & 0 & 0 \\
Predicated Theme & 1 & 1.4 & 0 & 0 & 0 & 0 \\
Thematized comment & 1 & 1.4 & 5 & 5.1 & 1 & 2.8 \\
\hline
\end{tabular}

The above table shows that predicated Theme is found in argumentative writings with very small percentage. For example:

(10) It is known to all that where there is a will, there is a way.

(2011.12)

Argumentative writing is characterized by the persuasive arguments, the final goal is to convince readers. Predicated Theme allows the writer to pick out a single element and give it emphatic thematic status so as to focus on the stressed argument.

Expositions use relatively more thematized comment structures. For example:

(11) It is undeniable that shopping on the Internet has become an irresistible trend in modern society.

(12) It is of great urgency that we should enforce relative laws in accordance with the repid growth of online shopping. (2011.6)

(13) It is urgent to let the students use computers in a proper way.

Halliday(1994:60) correlates this structure with "fact projection" and names it as "postposed subject". Thompson (2004: 216) holds that it is a special thematic structure, which allows the comments of speakers to be the starting point of information. Exposition usually tries to use accurate, reasonable and appropraite definition, judgement, interpretation, giving the reader a clear picture about what is being talked about. Thematized comment structure may help to reflect objective and true things as they are.

Table 6.7 Simple and Multiple Theme

\begin{tabular}{lllllll}
\hline \multirow{2}{*}{ Theme } & \multicolumn{2}{l}{ Argumentation } & \multicolumn{2}{c}{ Exposition } & Letters & \\
\cline { 2 - 7 } & No & $\mathbf{\%}$ & No & \% & No & \% \\
\hline Total & $\mathbf{7 0}$ & & $\mathbf{9 9}$ & & $\mathbf{3 6}$ & \\
Simple & 17 & 24.2 & 34 & 34.3 & 24 & 66.7 \\
Multiple & 34 & 48.6 & 32 & 32.3 & 13 & 36.1 \\
\hline
\end{tabular}

Largest number of multiple Themes appear in argumentation, second and third largest in exposition and letter. In letter writings, $66.7 \%$ of the Themes are simple Themes, which is determined by the character of letter writing. The purpose of writing letter is to express clearly what the writer wants to say, what the writer wants the reader to know, the content must be manifest at a glance. For example:

(14) My parents will also be happy to see you again.

(15) A river lies not far away from my home.

(16) I'm very luck to attend this world-famous university.

(17) These suggestions are not just of my own, but also of many other students. (2002.1)

Argumentation tends to use logical methods and direct words to show ideas or opinions, intellectually convincing readers for the purpose of the article. Exposition describes and explains things objectively, putting its emphasis on introducing calmly and objectively rather than arbitrarily. Sometimes, method of narration, describing, and argumenting will be applied in exposition owing to the needs of expression, which can be the supplement to help achieve the purpose of transmission of knowledge and methods to readers. It is not strange that more multiple Theme appear in those two types of writings. The following italized ones show that:

(18) From the stopping track on the road, it is clear that the two taxis were driving too fast. (2003.6)

(19) Firstly, it helps protect the living surroundings, build a healthy society and promote low-carbon life. (2008.12)

(20) For one thing, we should appeal to our authorities to legislate strict laws and regulations to protect these museums. (2009.6)

(21) Unfortunately, it doesn't help children to become self-reliant. (2010.12) 
Table 6.8 Theme in Imperative Clause, Clause Complex and Existential "there" Theme

\begin{tabular}{lllllll}
\hline \multirow{2}{*}{ Theme } & \multicolumn{2}{l}{ Argumentation } & Exposition & \multicolumn{2}{l}{ Letter } \\
\cline { 2 - 7 } & No & $\mathbf{\%}$ & No & \% & No & \% \\
\hline Total & $\mathbf{7 0}$ & & $\mathbf{9 9}$ & & $\mathbf{3 6}$ & \\
Imperative & 0 & 0 & 6 & 6.1 & 1 & 2.8 \\
Clause complex & 5 & 7.1 & 9 & 9.1 & 7 & 19.4 \\
Existential & 1 & 1.4 & 3 & 3.0 & 0 & 0 \\
\hline
\end{tabular}

Expositions have absolutely more imperative clauses. The different percentages of Themes in clause complex are not so distinct in argumentation and exposition. Expositions have more existential "there" in Theme.

Imperative clauses are used to ask, request, command or sugget others do or not do a thing. Comparing with argumentation, exposition gives more suggestions to inform. For example:

(22) Don't be proud, and neither too timid.

(2001.1)

(23) Encourage children to work out issues themselves, and to approach parents only if someone is in danger or the problem is very difficult to deal with.

A clause complex involves a head clause together with other clauses that modify it. It is a combination of clauses relating paratactically or hypotactically but not through embedding; the mode of combination is the mode of organization of the logical subtype of the ideational metafunction. For example, clauses combined through coordination form a clause complex. The notion of "clause complex" thus enables us to account in full for the functional organization of sentences (cf. Halliday 1994: 216). Both argumentaion and exposition use clause complex as Theme, the reason might be that simple Themes or other multiple Themes are not enough to convince others and to explain clearly. By the way, the use of caluse complex as Theme can make writings more diverse and logical, which can be examflified in the following examples:

(24) As far as the preparation work is concerned, you should first of all review all the required vocabulary. (2004.1)

(25) If they try, and don't know how to complete a task, offer them help, but teach them how to do the task rather than doing it for them. (2010.12)

While in the sample writings of letters, 5 clause complexes are used as Theme in one letter, which is a reply to a friend, constituting $78 \%$ of the total number. This paper does not consider it as a data for analysis for it is not convincing enough.

As is mentioned above, exposition is a type of discourse that is used to explain, describe, give information or inform, it tends to use accurate, reasonable and appropriate definition, judgment, interpretation so as to maintain its scientific character. The creator of an expository text can not assume that the reader or listener has prior knowledge or prior understanding of the topic that is being discussed. Therefore, the existential "there" structures can be used to show objective aspects. See the following example.

(26) There are various factors that triggered the phenomenon.

Till now, the answers to the first two research questions raised in the first part are shown obviously. Theme is an aspect of language which does yield useful information and successful writings have various theme types. The above tables are the best proofs. No matter what kind of writing it is, different Themes are used to make the writing more diversified, fluent and cohesive.

\subsection{An Analysis on Thematic Progression Patterns}

The notion of TP concerns the ways that texts develop the ideas they present. More specifically, TP concerns where Themes come from and how they relate to other Themes and Rhemes of the text. Patterns of TP are formed by a systematic relation between the Theme-Rheme selections and experiential selections in a text.

As is mentioned above, the choices of clause Themes play a fundamental part in the way discourse is organized; it is this, in fact, which constituents what is often known as the "method of development" of the text. If the "method of development" does play a vital role in the organization of the discourse, it would be interesting to know how the thematic development is manifested in the written texts. TP Patterns are the first things to notice as for the method of development. In this part, TP Patterns of the selected sample writngs will be analysed. Themes are underlined, Rhemes are not.

\section{Nothing Succeeds Without a Strong Will}


$\underline{I t(T 1)}$ is known to us all that where there is a will, there is a way(R1). A person(T2) can probably accomplish nothing without a strong will(R2). We(T3) can't deny that sometimes people can reach a goal by playing tricks(R3); however, that (T3') definitely won't last long.

People with strong wills(T4) cannot be def $\downarrow$ eated by difficulties easily(R4) and they(T4') will never give up untill they succeed(R4'). Take Nobel(T5), the inventor of explosive, as an example, before inventing explosive he took thousands of explosion experiments(R5). We(T6) can name quite a lot of famous people like NobeL(R6), but we(T6') can also list some people like the "smoking quitters" (R6'). To them(T7), making a plan is so easy as they don't have to keep it(R7). Therefore, they(T8) will never realize it (R8).

To sum up, a strong will(T9) is an important character people should cultivate since it plays a key role in people's success(R9). The resolute(T10) make resolutions once and for all(R10); the irresolute(T10') keep making resolutions all for once (R10'). To be the winneR(T11), try to be the resolute(R11). (2011.12)
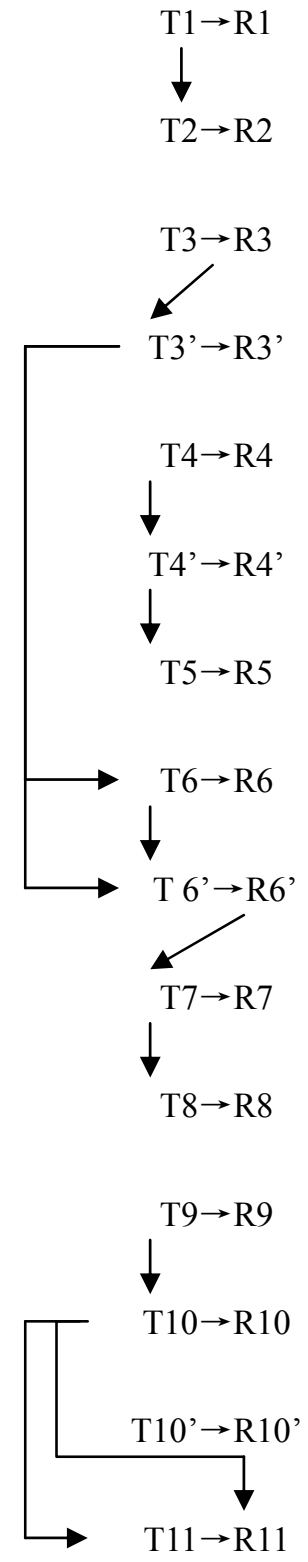

This article begins with a proverb, which paves the way for the main body. The Rheme in the second clause shows the same opinion with the Rheme in the first clause. By using concentrated progression here, the writer gives a further clarifying about his/her argument. In the next clause, R3=T3', "that" means "sometimes people can reach a goal by playing tricks", which expresses clear idea by using lest words. Besides, by using "however", the denial of 
this practice is obvious.

In the second paragraph, "people with strong wills" certainly includes "Nobel", this derived Theme helps the writer to use example to further elaborate the importance of a strong will. $\mathrm{T} 3=\mathrm{T} 6=\mathrm{T} 6$ ', "we" is a broad term which can be used to denote you and me. This article is a piece of argumentative writing, its aim is to convince readers of the writers argument, such broad term like "we" is of great necessity. R6' $=\mathrm{T} 7=\mathrm{T} 8$, this TP with constant Theme is used to comment on the phenomenon that some people quit smoking unsuccessfully repeatedly.

The last paragraph is a conclusion for the whole article. $\mathrm{T} 9=\mathrm{T} 10=\mathrm{T} 11$, this parallel progression pattern helps to reiterate the importance of having a strong will. Different terms are used to describe the same kind of people, " $a$ strong will" means "the resolute" people and "the winner", which plays the role of emphasis as well as avoiding the repeated use of same expression.

\section{How Should Parenets Help Children to Be Independent}

Nowadays some parents(T1) tend to take on everything concerned with their children(R1). Most of them(T2) do this out of love, hoping they can craft the perfect childhood for their kids and give their children the best possible shot at success in life(R2). Unfortunately, it(T3) doesn't help children to become self-reliant(R3).

To help their children develop independence, here(T4) are some tips for parents(R4). First, give(T5) children increasing responsibility(R5). Teach(T6) children that they are important contributors to the family(R6), and give(T6') them age-appropriate chores(R6'). Second, encourage(T7) kids to try things themselves first(R7). If they try(T8), and don't know how to complete a task, offer them help, but teach them how to do the task rather than doing it for them(R8). Third, teach(T9) kids to solve their own disputes(R9). Encourage(T10) children to work out issues themselves, and to approach parents only if someone is in danger or the problem is very difficult to deal with(R10).

There(T11) is no single way to help children become independent(R11). However, as long as parents follow the advice mentioned above(T12), it's no hard to raise children to become independent adults(R12). (2010.12)
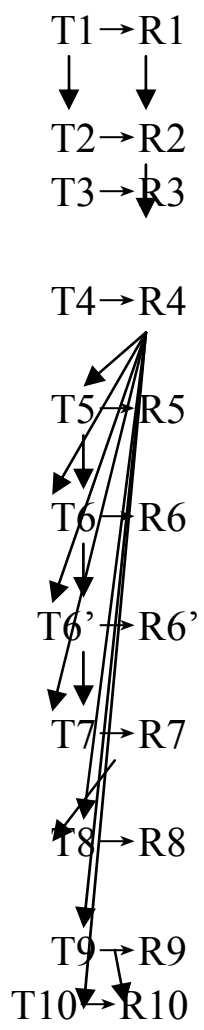

$\mathrm{T} 11 \rightarrow \mathrm{R} 11$

$\mathrm{T} 12 \rightarrow \mathrm{R} 12$ 
It is not very difficult for students to judge that this is a piece of expositive writing from the title. At the very beginning, the writer comes to the point directly by saying "Nowadays some parents tend to take on everything concerned with their children". From the analysis above we can see that $\mathrm{T} 1=\mathrm{T} 2$, this parallel progression pattern helps to make the previous point continue. Obviously, T5,T6,T7,T8,T9,T10 are the tips mentioned in R4, this split-Rheme pattern forms a general-specific structure, which presents ideas clearly and logically. Since it is an article to tell parents what to do with their children, $\mathrm{R} 5=\mathrm{R} 6=\mathrm{R} 6{ }^{\prime}=\mathrm{R} 7$, this concentrated pattern correponds to the tips mentioned in T5,T6,T7. There is a TP with constant Theme, R7=T8, in which the writer gives out an example to show the details of the second tip, aiming to make the explanation comprehensive. R9=R10, this concentrated Theme pattern is the continuation of the former tips. Although there are no any TP patterns, the last paragraph echoes the main topic of this article successfully by using "there be" structure and "However".

\section{A letter}

January $12^{\text {th }}, 2002$

Dear Mr. President,

I(T1)'m very luck to attend this world-famous university(R1), but I(T1')'m afraid I'm not content with the canteen service on campus(RI').

Firstly, the quality of the dishes(T2) should be improved(R2). Undoubtedly, there(T3) are a lot of delicious dishes(R3), but all the year round, they(T3') are the same(R3'). More and more students(T4) are complaining about eating the same food each day(R4). So I(T5) think the most urgent problem is variety(R5).

Secondly, the price(T6) is a bit too high(R6). Many of us(T7) hope that the canteen can provide us with not only delicious but also cheaper food(R7).

Finally, the environment(T8) is so noisy that we can't enjoy our meals in good mood(R8). I(T9) suggest that there be some soft music to help us relax(R9).

These suggestions(T10) are not just of my own, but also of many other students(R10). We(T11) hope our respectable president will pay attention to out suggestions(R11).

$\underline{B y}$ the way, the canteen workers(T12) are very patient and always smiling(R12). So I(T13) think if our university offers them better conditions, they will offer us better service(R13).

Best wishes,

Yours sincerely
Liming


This is a piece of sample writing of CET-4 from January, 2002. Obviously, not too many TP patterns are applied in this letter. This may explain the reason why this letter seems pedestrain, comparaing with the other samples. The other reason might be the increasingly high demand of CET-4, the sample letter from January 2004 uses more patterns like parallel pattern, intersectional pattern, etc,. which can be seen in Appendix I. Besides, Themes in the latter one are more diverse. Choosing this sample letter, the study wants to make a comparision to show how important the application of TP patterns is. This is a letter from a student to the president of the university. The student gives some suggestions about improving the canteen service. The writer expresses his honor of being a student in this university, then a parallel pattern, $\mathrm{T} 1=\mathrm{T} 1$ ' helps to form a turning point to propose the following suggestions. The second paragraph begins with the quality of the dishes, which is part of the canteen service, this split Rheme pattern is of great significance in the transition from paragraph one to paragraph two. The following third and fourth paragraphs continue the suggestions from the aspects of price to environment. Paragraph five tells the writer's hope that the president can pay more attention to the suggestions because these are not just from him/her, but from many other students. The last paragraph mentions the patient canteen workers, calling for better condition for them. Anyhow, this is a common letter which does show clear the purpose of writing it.

Not all the sample writings will be analyzed in the above way in this paper owing to the space limitation and there is no much neccessity for doing this. This paper analyzese all the samples and makes the result shown in the following table. The data in the following table shows the comparision between different TP patterns applied in different genre types.

Table 6.9 TP Patterns in All Samples

\begin{tabular}{lllllll}
\hline \multirow{2}{*}{ Genre type } & \multicolumn{2}{l}{ Argumentation } & \multicolumn{2}{l}{ Exposition } & \multicolumn{2}{l}{ Letter } \\
\cline { 2 - 8 } & No. & $\mathbf{\%}$ & No. & $\mathbf{\%}$ & No. & \% \\
\hline Total clauses & $\mathbf{7 0}$ & & $\mathbf{9 9}$ & & $\mathbf{3 6}$ & \\
Parallel & 8 & 11.4 & 9 & 9.1 & 4 & 11.1 \\
Continuous & 0 & 0 & 1 & 1.0 & 0 & 0 \\
Intersectional & 3 & 4.3 & 2 & 2.0 & 1 & 2.8 \\
Coordinate & 0 & 0 & 2 & 2.0 & 0 & 0 \\
Derived Theme & 4 & 5.7 & 3 & 3.0 & 0 & 0 \\
Concentrated & 6 & 8.6 & 2 & 2.0 & 0 & 0 \\
Constant Theme & 3 & 4.3 & 5 & 5.1 & 0 & 0 \\
Split Rheme & 3 & 4.3 & 8 & 8.1 & 1 & 2.8 \\
\hline
\end{tabular}

The data in this table shows the answer to the third research question raised in the first part, Does Thematic progression correlate with genre type? If comparaing letter with the other two types of writing, the answer is quiet obvious. Argumentation and exposition use many more different TP Patterns. This well explains that different writing purposes need different writing methods. It seems that in letter writing, things can be made clear with not too many different TP Patterns. The purpose of writing letters is to make what one wants to say easy to be understood, too much thinking or time spent might not be a good idea. Argumentation and exposition are not the cases obviously, they all try to use beautiful and cohesive language to arouse readers' interest so that arguments can be accepted and explanation can be clearly expressed. That is why those two types of writings use more different types of TP Patterns. It is obvious that with the help of different TP Patterns, writings become more logical and coherent.

\section{Application of the Theories in Writing Teaching Practice}

As can be seen from the previous analysis, successful writings do have various Theme types and the TP patterns do help in the realization of cohesion and coherence of writing. A question following is that how to introduce the seemingly complicated theories to students in calss, because it is the first step if we want to apply the theories in writing teaching.

\subsection{Avoiding Explaining all Expressions and Definitions}

According to what has been introduced in previous part, different linguists have different criteria in classifying the types of Theme and TP Patterns, thus different expressions and definitions appear. In teaching practice, there is no need introducing all of them since we are facing with non-English majors. If doing so, things might be exactly 
contrary to what we wished. Students are not necessary to know all different linguistic schools, famous linguists. For them, knowing how to do seems more important than knowing why to do. Teachers are supposed to do lots of preparaing work before class, they can combine and separate different contents according to the needs of the class, choosing what are appropriate for teaching while students may not need to know which two theories are combined or separated. Besides, although so many researches about Theme and TP Patterns have been done, there are still uncertainty in some fields, teachers' task is to guide students to use the theories well in their writing, avoiding using uncertain terms is very inportant, otherwise, there will be great difficulty in writing teaching. Anyhow, we don not want to make students confused about different knids of expressions and definitions.

\subsection{Combining Theory with Genre Teaching}

In previous analysis, there is relationship between thematic choices, TP Patterns and genre types. For example, argumentative writing favors more multiple Themes while expositive favors imperative clauses, which are regarded as the results of influence of different genre types. In teaching practice, theory introduction can be different according to what kind of writing is to be taught. By doing this, students can develop more awareness in applying different methods in different genre writings.

The detailed genre teaching methods will be introduced in 4.4.

\subsection{Noticing Cohesion and Coherence in Applying the Theories}

According to the detailed analysis in the previous part, a piece of writing may use various kind of Themes and TP Patterns, which is thought to make writings more diversified, more importantly, more fluent and coherent. That is to say, the application of the theories can also be regarded as special cohesive devices. Teachers should mention this point in writing teaching so that students will make clear about why they need to learn those theories. How to realize cohesion and coherence in writing teaching will be illustrated in 4.3 in details.

\subsection{Realization of Cohesion and Coherence with The Help of Thematic Choices and Thematic Progression Patterns}

Many students spend a lot of effort in avoiding syntax errors but ignore the appropriate expression of his thoughts. Many teachers tend to give guidance that correctness should be emphasized; the result will be less grammatical mistakes but more inaccurate wordings, the mixture of spoken and written language, unsmooth article, laying out obscurity for reading. Besides, learners put more attention on grammar learning without noticing that the language potential has already provide them with a lot of choices, not to say considering the choice of words, syntax and textual structure carefully.

Each author has his/her own intention when writing. Every article has its own central idea. The arrangement of the article must focus on them. That is to say there is intrinsic relationship between paragraphs and sentences, which can be shown in certain form. The relationship is coherence, while the method by which we use to perform such kind of relationship is cohesion.

\subsection{Cohesion, Coherence and Different Thematic Choices}

According to the previous analysis, the fluency, cohesion and coherence of discourse, to some extent, can be decided by different thematic choices. In daily writing teaching, much attention should be paid to cohesion and coherence with the help of choosing appropriate Themes.

Taking the text structure analysis from New Horizon College English (NHCE) One, Unit 3 as an example, the purpose of the exercise is to help students know the text structure well and prepare for writing practice. This is a good chance to do writing training with the help of analyzing thematic choices. According to the exercise, the whole structure of the text is analyzed clearly by dividing it into two parts. Part one shows what time we make the most important impression on others or others leave the most important impression on us, and gives examples to prove the points. Part two is a list of advice on how to make a good impression on others during the first seven seconds. This passage is a piece of exposition; teachers can choose some of the findings from the previous analysis to facilitate the teaching of this passage. For example, according to previous findings, expositions have more imperative clauses and relatively more multiple Themes. See the following examples:

(27) Focus on the first seven seconds. (para.2)

(28) Be yourself. (para.6)

(29) Use your eyes. (para.10)

(30) If you follow all this advice, you will drive everyone crazy. (para.6)

(31) If I did agree, I certainly wouldn't look at my feet or at the ceiling. (para.11) 
Those findings can be offered before text analysis, students are supposed to check the truth of the findings so that they may have more deep impression on the features of such type of writing. Or teachers can ask students to analyze first about the thematic choices of some paragraphs, ie, paragraph 3,6,10. There will be no difficulty for students finding out what kind of Themes are used often to give out advice and how the text become coherent by using different Themes.

Certainly, the analysis of TP Patterns can also be applied here, which is sure to make students get more clear picture about the organization of the text, how cohesion and coherence are achieved by choosing right TP Patterns.

\subsection{Adhering to "Clause-Paragraph-Text" Training Program}

Close attention should be paid to the basic skill training at the beginning of the writing stage so that good writing habit can be established. For college students, they have mastered basic language skills, grouping words into clauses, clauses into paragraphs and practicing writing small pieces of article according to different genres might be a better training method, since it helps to improve the syntactic proficiency in writing. In practice, teachers should proceed from the simple to the complex, from the easy to the difficult.

An article is made up of several paragraphs, so finishing a paragraph logically and fluently will lay foundation to a successful writing. There will be chaos if the unity and continuity of the article is missing. In daily practice, most teachers tend to make more efforts in teaching the mapping out the writing, i.e., bringing out the theme at the very beginning, putting topic sentence at the beginning, etc,. One thing should not be forgotten, that is the clarifying of the logical relationship between clauses. No single clause is isolated; there must be some association among different clauses. One major task for teacher is to help clarify how different Themes and Rhemes are related in the realization of transition from clause to clause, from paragraph to paragraph, how different TP Patterns are used and why they are used will be of importance in forming adhesive and cohesive discourse, ie, in the first paragraph of sample writing from January, 2002, a parallel progression pattern is used to help to form a turning point to propose the following suggestions.

\subsection{Understanding the Differences between English and Chinese Expressions}

Knowing the differences between English and Chinese expression is another significant factor in writing successfully. As for cohesion and coherence, both English and Chinese pay much attention to them. However, owing to different ways of thinking, Chinese tend to start a topic from periphery, then get to the point; people in English speaking countries tend to get to the point first to show their point of view, some peripheral arguments will then be offered as supplements. For Chinese students, they have got used to Chinese expressions so much that it is a little bit hard to change their habits. Great efforts are needed to remind them of the differences with persistence, i.e., on spatial description, Chinese prefers the way from the far to the near, English vice versa; the realization of coherence in English relies on the well use of conjunctions, which can reflect the integrity and carefulness in organizing ideas.

\section{Conclusion}

The research questions proposed at the very beginning of the paper have been answered. Theme is an apect of language which can yield useful information. Successful writings do have various theme types. A tenative conclusion is drawn that TP correlates with genre type to some extent. The use of TP Patterns can improve English writing in the aspects of cohesion, coherence, forming logical ideas and logical writings, etc,.

What is more, the application of the theories in this study is not isolated, it has a lot to do with realization of cohesion, coherence in discourse; it also relates with genre types to some extent. The study tries genre approach in writing teaching, hoping it will be of help for teaching writing in college.

Traditional writing teaching methods focus on the spelling of words and correct use of grammar, but do not provide students with specific instruction for developing a coherent composition. This paper has proved that the application of Theme and TP Patterns is a useful and practical teaching method in college English writing. Here are some of its pedagogical implications.

First, Theme and TP can benefit students' writings in the aspect of cohesion and coherence. While in the process of teaching the theories, teachers can not rush things through to completion, different strategies should be used.

Second, TP helps students get rid of illogical and disordered thread of thought. TP Patterns reflect the inter-clause relations, which can make students clearly aware of the relation between one clause and another, there will be no "wandering-off" in their writings. 
Third, TP provides students a practical method to develop a composition. When sufferring from mental blocks when students start a composition especially on the occasions of CET-4, TP offers them a specific solution.

Fourth, SFL does offer a good method for writing teaching by applying the theories of Theme and TP Patterns. However, teaching process is a changing one, sometimes, one strategy is enough in guiding students, while other times, different ways are needed to be combined together.

This paper mainly focuses its attention on three types of writing, namely, argumentation, exposition and letter. It has been proved that TP Patterns correlate with genre types, thus genre teaching might be another good way to teach writing in college. In a word, there is no perfect study, researches are always moving forward with lots of difficulties and challenges. There is no exception for the present study. It is only hoped that this paper can contribute a little in college writing teaching.

\section{References}

Celce-Murcia, M., \& Larsen-Freeman, D. (1999). The Grammar Book: An ESL/EFL Teacher's Course (2 ${ }^{\text {nd }}$ ed.). London: Heinle ELT.

Cheng Jingying. (1994). An Analysis on English Writing Teaching. Foreign Language Teaching and Research, 2, 66-70.

Danes, F. (1974). 'Functional Sentence Perspective and the organization of the text', in Papers on Functional Sentence Perspective (Janua Linguarum, Ser. Minor, 147) ed. By F.Danes. The Hague: Mouton, 106-28. http://dx.doi.org/10.1515/9783111676524.106

Firbas, J. (1986). On the dynamics of written communication in light of the theory of functional sentence perspective. In C. Cooper and S. Greenbaum (eds), Studying writing: linguistic approaches. London: Sage, pp. 40-71

Francis, B. (1989). Thematic selection and distribution in written discourse. Word, 40, 201-221. http://dx.doi.org/10.1080/00437956.1989.11435804

Fries \& Peter H. (1995). Themes, methods of development, and texts. In Hasan and Fries(Eds.), On Subject and Theme: From the perspective of Functions in Discourse. Amsterdam: John Benjamins., pp. 317-359

Greenia. (1992). Foreign Language Annals. The Hague: Mouton.

Halliday, M.A.K. (1967). Notes on transitivity and theme in English, Parts 1 and 2. Journal of Linguistics, 3(1), 37-81. http://dx.doi.org/10.1017/S0022226700012949

Halliday, M.A.K. (1985). An Introduction to Functional Grammar. London: Edward Arnold.

Halliday, M.A.K. (1994). An Introduction to Functional Grammar(2 ${ }^{\text {nd }}$ ed.). London: Edward Arnold.

Halliday, M.A.K., \& Matthiessen, C.M.I.M. (2004). An Introduction to Functional Grammar ( ${ }^{\text {rd }}$ ed.). London: Edward Arnold., xz.

Hatim, F. (2001). Communication across cultures: translation theory and contrastive. Berlin: Mouton de Gruyter.

Hu Zhuanglin. (1994). Cohesion and Coherence of Discourse. Shanghai: Shanghai Foreign Language Education Press.

Kopple, W.J. (1991). Themes, thematic progressions, and some implications for understanding discourse. Written Communication, 8(3), 311-347. http://dx.doi.org/10.1177/0741088391008003002

Li Changzhong. (2002). Cohesion, coherence and College English Writing. Foreign Language Teaching and Research, 11, 66-70.

Liu Chendan. (1999). Text Linguistics for Teachers. Shanghai: Shanghai Foreign Language Education Press.

Martin, J.R. (1985). Intrinsic functionality: implications for contextual theory. Social Semiotics, 1(1), 99-162. http://dx.doi.org/10.1080/10350339109360331

McCarthy, M. (1991). Discourse analysis for language teachers. Cambridge: CUP. North, S. 1987. The making of knowledge in composition. London: Heinemann.

Nwogu, K., \& Bloor, T. (1999). Thematic progression in professional and popular medical texts. In Ventola, E(ed.), Functional arid systemic linguistics: Approaches and uses(369-384). Berlin: Mouton de Gruyter.

Ravelli, L.J. (forthcoming). (1996). Metafunctional interaction from a dynamic perspective: implications for the 
description of Theme. To appear in R. Hasan and P.H. Fries (eds.), On Subject and Theme: From the Perspective of Functions in Discourse. Amsterdam: John Benjamins.

Ren Liqing. (2005). The Samples of Writing for CET-4. Beijing: China Translation \& Publishing Corporation.

Thompson, G. (2004). Introducing Functional Grammar. UK: Hodder Arnold.

Van Dijk, T.A. (1981). Studies in the pragmatics of discourse. The Hague/Berlin: Mouton. http://dx.doi.org/10.1515/9783110826142

Wang Hongguang. (2002). On the Cultivation of Students' Writing Ability by the Process Genre Approach. Journal of Huazhong Normal University(Humanities and Social Sciences), 1, 142-143.

Wu Jin. (2000). New Exploration on English Writing Teaching. Foreign Language Teaching and Research, 3, 15-21.

Xu Shenghuan. (1982). Theme and Rheme. Foreign Language Teaching and Research, 1, 1-9.

Zhu Yongsheng. (1995). Thematic Progression Patterns and Discourse Analysis. Foreign Language Teaching and Research, 5, 6-12. 